\title{
The association between serum 25-hydroxyvitamin D concentrations and serum lipids in the Southern Thai population
}

\author{
Nutjaree Jeenduang ${ }^{1,2}$, Boonnisa Sangkaew ${ }^{1}$
}

\begin{abstract}
${ }^{1}$ School of Allied Health Sciences, Walailak University, Nakhon Si Thammarat, Thailand ${ }^{2}$ Food Technology and Innovation Research Center of Excellence, Walailak University, Nakhon Si Thammarat, Thailand
\end{abstract}

Submitted: 21 November 2018; Accepted: 5 April 2019

Online publication: 20 November 2020

Arch Med Sci 2022; 18 (1): 11-17

DOI: https://doi.org/10.5114/aoms.2020.101100

Copyright $\odot 2020$ Termedia \& Banach

\begin{abstract}
Introduction: Dyslipidaemia is a major risk factor for cardiovascular diseases (CVD). Vitamin D deficiency has been found to be associated with CVD. However, the relationships between vitamin $D$ and lipids are inconsistent. The aim of this study was to investigate the relationship between vitamin $D$ status and serum lipids in Southern Thai subjects.

Material and methods: A total of 726 healthy subjects in Southern Thailand were enrolled in the study. Serum 25-hydroxyvitamin D $(25(\mathrm{OH}) \mathrm{D})$, lipid profiles, fasting plasma glucose, anthropometric data, blood pressure, and body composition were measured. The relationship between serum $25(\mathrm{OH}) \mathrm{D}$ levels and biochemical data was evaluated by partial correlation and multiple linear regression analyses. The association of serum 25(OH)D levels with dyslipidaemia was analysed using multivariate regression analysis.

Results: Serum 25(OH)D levels were negatively correlated with body mass index (BMI), total cholesterol (TC), triglyceride (TG), low-density lipoprotein cholesterol (LDL-C), and body composition parameters after adjusting for age in women. Multiple linear regression analysis showed that TC and $\mathrm{BMI}$ were independent predictors for $25(\mathrm{OH}) \mathrm{D}$ concentrations in women. Multivariate logistic regression analysis showed that the odds ratio of hypertriglyceridaemia $(\mathrm{OR}=0.51 ; 95 \% \mathrm{Cl}: 0.32-0.80, p=0.004)$ and reduced high-density lipoprotein cholesterol (HDL-C) $(\mathrm{OR}=0.43 ; 95 \% \mathrm{Cl}: 0.26-0.71$, $p=0.001)$ were significantly lower in vitamin D sufficiency when compared with hypovitaminosis $D$ in women.

Conclusions: Vitamin D sufficiency could reduce risk of hypertriglyceridaemia and reduced HDL-C, particularly in women, suggesting that vitamin D sufficiency may have beneficial effects on lipids and a decreased risk for CVD in Thai women.
\end{abstract}

Key words: 25-hydroxyvitamin D, dyslipidaemia, serum lipids.

\section{Introduction}

Vitamin D is a lipid-soluble hormone that is mostly synthesised from skin when exposed to ultraviolet B irradiation (280-320 nm) from sunlight [1]. A minor source of vitamin $D$ could be derived from dietary intake of fish, cereals, dairy products, and vitamin D supplements [2]. Vitamin D has been known to be associated with calcium metabolism and bone mineralisation [3]. Vitamin D deficiency results in osteomalacia, osteoporosis, and

\author{
Corresponding author: \\ Nutjaree Jeenduang PhD \\ School of Allied Health \\ Sciences \\ Walailak University \\ Nakhon Si Thammarat, \\ Thailand \\ Phone: +6675672678 \\ E-mail: nutjaree.je@wu.ac.th
}


increased risk of fractures [3]. However, recent data from various studies has demonstrated that vitamin $D$ deficiency may be associated with several chronic diseases including cancer, infections, autoimmune disease, cardiovascular disease (CVD), diabetes mellitus, and microbial infection [4-8].

Several mechanisms of vitamin D in developing CVD have been proposed. Previous studies have supported that vitamin $\mathrm{D}$ plays an important role in reducing the risk of CVD by inhibiting the renin-angiotensin system, reducing parathyroid hormone levels, decreasing coagulation, reducing inflammation, and then reducing atherosclerosis and increasing insulin production [9]. In addition, vitamin D could prevent CVD through the regulation of several genes that are involved in cellular differentiation, proliferation, apoptosis, and angiogenesis [3]. Moreover, another proposed mechanism for the protective effect of vitamin $D$ on CVD is the regulation of lipid profiles. Several cross-sectional studies have reported an association between vitamin D and lipid levels [10-26]. Nevertheless, some reports have shown that there is no association between vitamin $\mathrm{D}$ and lipid levels $[27,28]$. Thus, the relationship between 25 -hydroxyvitamin D $(25[\mathrm{OH}] \mathrm{D})$ levels and serum lipids is inconsistent among various studies.

In Southern Thailand, dyslipidaemia, which is an independent modifiable risk factor for CVD $[29,30]$, has been found to affect more than $50 \%$ of people [31]. Additionally, the prevalence of vitamin D deficiency (6.30\% to $6.91 \%)$ and vitamin D insufficiency $(43.74 \%$ to $43.80 \%)$ is highest when compared with other regions of Thailand [32, 33]. This may be due to the Southern Thai population having a higher percentage of Muslims [33]. Furthermore, the association between vitamin D status and lipid levels has not been reported yet in Southern Thailand. Thus, the aim of this study was to evaluate the relationship between 25(OH)D levels and serum lipids among the Southern Thai population.

\section{Material and methods}

\section{Study subjects}

The study group included 726 individuals from the Kiriwong and Bansakha districts of Nakhon Si Thammarat in Southern Thailand. Body mass index (BMI) and waist circumference (WC) were recorded. Systolic blood pressure and diastolic blood pressure were measured. Body composition including body fat percentage, fat mass, fat free mass (FFM), muscle mass, and visceral fat rating were all measured using Bioelectric Impedance Analysis, Tanita SC-330 (Tanita Corp, Japan). Exclusion criteria for subjects were the presence of chronic disease, thyroid disease, renal or hepatic disease, the use of hormone replacement therapy or lipid lowering agents, and drug abuse. The study protocol was approved by the Ethics Committee of Walailak University (protocol no. 14/101). Written informed consent was obtained from all subjects before being included in the study.

\section{Data collection}

Demographic data were obtained using a questionnaire. The questionnaire was conducted by well-trained interviewers and contained information on age, gender, smoking (yes, no), alcohol intake (current, former, never), physical activity (yes, no), education (Bachelor, secondary school, primary school, none), residential area (coastal, inland), religion (Buddhist, Muslim), intake of multivitamins (yes, no), intake vitamin D supplements (yes, no), intake of fish oil (yes, no), frequency of milk consumption (daily, $\geq 1$ to 6 days per week, no), use of sunscreen (yes, no), sunlight exposure (<30 min/day, $\geq 30 \mathrm{~min} /$ day), chronic diseases, medications, and family history of diseases.

\section{Laboratory analysis}

Blood samples were collected from subjects after $12 \mathrm{~h}$ fasting. The serum and plasma were separated by centrifugation at $3000 \mathrm{rpm}$ for 10 min. Serum total cholesterol (TC), high-density lipoprotein cholesterol (HDL-C), and triglycerides (TG) were measured using the standard enzymatic method. Low-density lipoprotein cholesterol (LDL-C) was calculated using the Friedewald formula. Fasting plasma glucose (FPG) was measured using glucose oxidase method. All tests were performed by using a Konelab analyser (KONELAB 20, Tokyo, Japan). Serum 25(OH)D levels were measured with an electrochemiluminescent immunoassay (VITROS $® 25-\mathrm{OH}$ Vitamin D Total Assay) on an automated machine (Vitros ECi, Johnson and Johnson, Rochester, NY, USA).

\section{Diagnostic criteria}

Dyslipidaemia was defined according to the NCEP ATPIII guidelines [34]. High TC was defined as TC $\geq 200 \mathrm{mg} / \mathrm{dl}$, high TG was defined as a serum TG level $\geq 150 \mathrm{mg} / \mathrm{dl}$, high LDL-C was defined as serum $\mathrm{LDL}-\mathrm{C} \geq 130 \mathrm{mg} / \mathrm{dl}$, and reduced HDL-C was defined as serum $\mathrm{HDL}-\mathrm{C}<40 \mathrm{mg} / \mathrm{dl}$ in men and HDL-C $<50 \mathrm{mg} / \mathrm{dl}$ in women. Based on an Endocrine Society Clinical Practice Guidelines [35], 25(OH)D of $30 \mathrm{ng} / \mathrm{ml}$ or greater was defined as sufficient, $25(\mathrm{OH}) \mathrm{D}$ of 20 to $29.9 \mathrm{ng} / \mathrm{ml}$ was defined as insufficient, and 25(OH)D of less than $20 \mathrm{ng} / \mathrm{ml}$ was defined as vitamin D deficient. Hypovitaminosis D was defined as $25(\mathrm{OH}) \mathrm{D}$ of less than $30 \mathrm{ng} / \mathrm{ml}$.

\section{Statistical analysis}

All data were analysed using SPSS (SPSS Inc., Chicago, IL; Version 17). Data were tested for nor- 
mality. Continuous variables were expressed as mean, and standard deviation and categorical variables were presented as a percentage. Differences between 2 groups were tested using Student's $t$-test for parametric, Mann-Whitney $U$ Test for non-parametric for continuous variables, and the $\chi^{2}$ test for categorical variables. Partial correlation analysis was used to assess the relation between serum 25(OH)D and biochemical parameters after adjusting for age. Multiple linear regression analysis was used to evaluate the independent effect of lipids, FPG, and BMI on serum 25(OH)D after adjusting for the confounders. The association of vitamin D status and dyslipidaemia was evaluated using logistic regression analysis. Confounders included the following: age, smoking, alcohol intake, physical activity, education, residential area, religion; intake of multivitamins, vitamin D supplements, or fish oil; milk consumption, the use of sunscreen, and sunlight exposure. A p-value $<0.05$ was considered statistically significant.

\section{Results}

Characteristics of the study subjects are summarised in Table I. The demographic characteristics of the study subjects are shown in Supplementary Table SI. A total of 726 subjects participated, of whom $19.97 \%$ were men and $80.03 \%$ were women. The age of the subjects ranged from 19 to 84 years. Men had significantly higher $25(\mathrm{OH})$
D levels, visceral fat, FFM, muscle mass, and bone mass, but lower BMI, percentage fat, and fat mass, compared with women. There were no significant differences in other parameters.

A comparison of characteristics of different vitamin D statuses according to gender is shown in Supplementary Table SII. The vitamin D status was categorised into 2 groups of hypovitaminosis $D$ and vitamin $D$ sufficiency because of the low number of subjects with vitamin D deficiency, particularly in men. BMI, WC, TC, TG, LDL-C, visceral fat, percentage fat, fat mass, FFM, muscle mass, and bone mass were significantly higher in hypovitaminosis D compared to vitamin D sufficiency in women. Moreover, the prevalence of hypertriglyceridaemia and reduced HDL-C was significantly higher in hypovitaminosis $D$ compared to vitamin $D$ sufficiency in women. However, these parameters were not significantly different in men.

The correlations of clinical parameters and serum 25(OH)D are shown in Table II. 25(OH)D was negatively correlated to BMI, WC, TG, percentage fat, and fat mass in both men and women after adjusting for age, whereas 25(OH)D was negatively correlated to TC, LDL-C, visceral fat rating, FFM, and bone mass only in women after adjusting for age. Multiple linear regression analysis was used to assess the independent factors of lipids, FPG, and $\mathrm{BMI}$ on serum $25(\mathrm{OH}) \mathrm{D}$ concentrations after controlling for confounders, as shown in Supplementary Table SIII. TC and BMI were significant in-

Table I. Characteristics of the study population

\begin{tabular}{|c|c|c|c|c|}
\hline Variables & $\begin{array}{l}\text { All subjects } \\
(N=726)\end{array}$ & $\begin{array}{c}\text { Men } \\
(n=145)\end{array}$ & $\begin{array}{l}\text { Women } \\
(n=581)\end{array}$ & $P$-value \\
\hline Age [years] & $53.31 \pm 13.52$ & $53.06 \pm 13.52$ & $53.38 \pm 13.53$ & 0.809 \\
\hline $\mathrm{BMI}\left[\mathrm{kg} / \mathrm{m}^{2}\right]$ & $24.43 \pm 4.14$ & $23.31 \pm 3.51$ & $24.71 \pm 4.24$ & $<0.001$ \\
\hline$W C[\mathrm{~cm}]$ & $84.92 \pm 11.11$ & $83.81 \pm 10.30$ & $85.20 \pm 11.30$ & 0.138 \\
\hline $\mathrm{SBP}[\mathrm{mm} \mathrm{Hg}]$ & $131.36 \pm 19.66$ & $129.56 \pm 17.77$ & $131.81 \pm 20.09$ & 0.175 \\
\hline $\mathrm{DBP}[\mathrm{mm} \mathrm{Hg}]$ & $79.78 \pm 12.07$ & $79.45 \pm 10.39$ & $79.86 \pm 12.46$ & 0.875 \\
\hline FPG [mg/dl] & $102.88 \pm 26.29$ & $104.37 \pm 25.70$ & $102.51 \pm 26.44$ & 0.159 \\
\hline $\mathrm{TC}[\mathrm{mg} / \mathrm{dl}]$ & $209.60 \pm 39.39$ & $207.86 \pm 38.95$ & $209.58 \pm 39.53$ & 0.922 \\
\hline $\mathrm{TG}[\mathrm{mg} / \mathrm{dl}]$ & $120.60 \pm 56.56$ & $125.72 \pm 58.99$ & $119.32 \pm 55.92$ & 0.233 \\
\hline $\mathrm{HDL}-\mathrm{C}[\mathrm{mg} / \mathrm{dl}]$ & $62.67 \pm 15.41$ & $62.59 \pm 17.12$ & $62.69 \pm 14.97$ & 0.713 \\
\hline LDL-C [mg/dl] & $122.44 \pm 36.68$ & $120.15 \pm 37.56$ & $123.01 \pm 36.46$ & 0.678 \\
\hline Visceral fat rating & $7.69 \pm 3.38$ & $10.01 \pm 4.62$ & $7.11 \pm 2.70$ & $<0.001$ \\
\hline Percentage fat (\%) & $31.88 \pm 17.98$ & $19.20 \pm 6.35$ & $35.05 \pm 18.55$ & $<0.001$ \\
\hline Fat mass [kg] & $19.16 \pm 8.09$ & $12.78 \pm 5.94$ & $20.75 \pm 7.77$ & $<0.001$ \\
\hline FFM [kg] & $40.50 \pm 6.97$ & $51.00 \pm 6.48$ & $37.88 \pm 3.98$ & $<0.001$ \\
\hline Muscle mass [kg] & $38.23 \pm 6.55$ & $48.22 \pm 6.16$ & $35.73 \pm 3.60$ & $<0.001$ \\
\hline Bone mass [kg] & $2.25 \pm 0.39$ & $2.66 \pm 0.32$ & $2.15 \pm 0.33$ & $<0.001$ \\
\hline $25(\mathrm{OH}) \mathrm{D}[\mathrm{ng} / \mathrm{ml}]$ & $30.56 \pm 8.35$ & $37.46 \pm 10.61$ & $28.84 \pm 6.65$ & $<0.001$ \\
\hline
\end{tabular}

$B M I$ - body mass index, WC - waist circumference, SBP - systolic blood pressure, DBP - diastolic blood pressure, FPG - fasting plasma glucose, TC - total cholesterol, TG - triglyceride, HDL-C - high-density lipoprotein cholesterol, LDL-C - low-density lipoprotein cholesterol, FFM - fat free mass, $25(\mathrm{OH}) \mathrm{D}-25$-hydroxyvitamin D. Data are presented as mean \pm standard deviation. 
Table II. Correlations of clinical parameters and serum 25-hydroxyvitamin D

\begin{tabular}{|lcccc|}
\hline Variables & \multicolumn{2}{c}{ Men $^{*}$} & \multicolumn{2}{c|}{ Women $^{*}$} \\
\cline { 2 - 5 } & $r$ & $P$-value & $r$ & $P$-value \\
\hline BMI $\left[\mathrm{kg} / \mathrm{m}^{2}\right]$ & -0.187 & 0.026 & -0.158 & $<0.001$ \\
\hline WC $[\mathrm{cm}]$ & -0.172 & 0.040 & -0.141 & 0.001 \\
\hline SBP $[\mathrm{mm} \mathrm{Hg}]$ & -0.138 & 0.101 & -0.011 & 0.784 \\
\hline DBP $[\mathrm{mm} \mathrm{Hg}]$ & -0.044 & 0.604 & -0.041 & 0.328 \\
\hline FPG $[\mathrm{mg} / \mathrm{dl}]$ & -0.023 & 0.787 & -0.081 & 0.052 \\
\hline TC $[\mathrm{mg} / \mathrm{dl}]$ & -0.131 & 0.119 & -0.174 & $<0.001$ \\
\hline TG $[\mathrm{mg} / \mathrm{dl}]$ & -0.195 & 0.020 & -0.195 & $<0.001$ \\
\hline HDL-C [mg/dl] & 0.064 & 0.446 & 0.007 & 0.861 \\
\hline LDL-C [mg/dl] & -0.103 & 0.219 & -0.130 & 0.002 \\
\hline Visceral fat rating & -0.137 & 0.102 & -0.156 & $<0.001$ \\
\hline Percentage fat $(\%)$ & -0.171 & 0.042 & -0.179 & $<0.001$ \\
\hline Fat mass $[\mathrm{kg}]$ & -0.179 & 0.033 & -0.161 & 0.001 \\
\hline FFM $[\mathrm{kg}]$ & -0.115 & 0.170 & -0.110 & 0.008 \\
\hline Muscle mass $[\mathrm{kg}]$ & -0.105 & 0.213 & -0.088 & 0.008 \\
\hline Bone mass [kg] & -0.130 & 0.123 & -0.110 & 034 \\
\hline
\end{tabular}

$B M I$ - body mass index, WC - waist circumference, SBP - systolic blood pressure, DBP - diastolic blood pressure, FPG - fasting plasma glucose, TC - total cholesterol, TG - triglyceride, HDL-C - high-density lipoprotein cholesterol, LDL-C - low-density lipoprotein cholesterol, FFM - fat free mass, *adjusted by age.

Table III. Odds ratio of dyslipidaemias by serum 25-hydroxyvitamin D levels

\begin{tabular}{|c|c|c|c|c|}
\hline \multirow[t]{3}{*}{ Variables } & \multicolumn{2}{|c|}{ Men } & \multicolumn{2}{|c|}{ Women } \\
\hline & \multicolumn{2}{|c|}{ Serum 25(OH)D } & \multicolumn{2}{|c|}{ Serum 25(OH)D } \\
\hline & $<30 \mathrm{ng} / \mathrm{ml}$ & $\geq 30 \mathrm{ng} / \mathrm{ml}$ & $<30 \mathrm{ng} / \mathrm{ml}$ & $\geq 30 \mathrm{ng} / \mathrm{ml}$ \\
\hline \multicolumn{5}{|c|}{ Elevated total cholesterol: } \\
\hline Unadjusted & 1 & $1.046(0.502-2.180)$ & 1 & $0.722(0.517-1.008)$ \\
\hline$P$-value & & 0.905 & & 0.056 \\
\hline Adjusted & 1 & $1.328(0.559-3.152)$ & 1 & $0.857(0.592-1.239)$ \\
\hline$P$-value & & 0.520 & & 0.411 \\
\hline \multicolumn{5}{|c|}{ Elevated triglyceride: } \\
\hline Unadjusted & 1 & $0.545(0.242-1.229)$ & 1 & $0.445(0.293-0.674)$ \\
\hline$P$-value & & 0.144 & & $<0.001$ \\
\hline Adjusted & 1 & $0.936(0.334-2.621)$ & 1 & $0.507(0.321-0.800)$ \\
\hline$P$-value & & 0.900 & & 0.004 \\
\hline \multicolumn{5}{|c|}{ Elevated LDL-C: } \\
\hline Unadjusted & 1 & $0.787(0.373-1.657)$ & 1 & $1.252(0.888-1.766)$ \\
\hline$P$-value & & 0.528 & & 0.200 \\
\hline Adjusted & 1 & $1.640(0.659-4.077)$ & 1 & $0.939(0.642-1.373)$ \\
\hline$P$-value & & 0.287 & & 0.746 \\
\hline \multicolumn{5}{|c|}{ Reduced HDL-C: } \\
\hline Unadjusted & 1 & $0.275(0.059-1.286)$ & 1 & $0.480(0.302-0.762)$ \\
\hline$P$-value & & 0.101 & & 0.001 \\
\hline Adjusted & 1 & $0.000(0.000-0.000)$ & 1 & $0.426(0.257-0.706)$ \\
\hline$P$-value & & 0.998 & & 0.001 \\
\hline
\end{tabular}

25(OH)D - 25-hydroxyvitamin D, LDL-C - low-density lipoprotein cholesterol, HDL-C - high-density lipoprotein cholesterol, *adjusted for age, body mass index, smoking, alcohol intake, physical activity, education, residential area, religion; intake of multivitamin, fish oil, or vitamin D supplement; milk consumption, the using of sunscreen, sunlight exposure.

dependent predictors for 25(OH)D concentrations in women.

Logistic regression analysis of $25(\mathrm{OH}) \mathrm{D}$ levels and dyslipidaemia is shown in Table III. Multivar- iate logistic regression analysis showed that the odds ratio of hypertriglyceridaemia and reduced HDL-C were significantly lower in vitamin D sufficiency when compared with hypovitaminosis $D$ 
$(p<0.05)$ after adjusting for confounders in women.

\section{Discussion}

The present study expanded on our prior work that showed the association between the VDR polymorphisms and MetS, as well as serum 25(OH)D levels in the Thai population [36] by investigating the association between vitamin $D$ status and lipid profiles in Thai subjects. In this study, high serum $25(\mathrm{OH}) \mathrm{D}$ levels were associated with a decreased risk for hypertriglyceridaemia and reduced HDL-C, particularly in women. Our results were consistent with previous studies of Chinese [11] and Korean Adults with prediabetes [12], and Canadian adults [13] in whom the highest serum 25(OH)D level showed a significant decrease in the prevalence of hypertriglyceridaemia and/or reduced HDL-C.

In addition, serum 25(OH)D was negatively correlated with TC, TG, and LDL-C levels in women, and negatively with TG in men after adjusting for age. Our findings were consistent with several previous studies in China [10, 14], Japan [15], Poland [16], the USA [17, 18], Korea [12], Finland [19], Germany [20], adults of European descent [21], Hispanic American adolescents [22], and a study from the US National Health and Nutrition Examination Survey 2001-2006 [23] in which serum $25(\mathrm{OH}) \mathrm{D}$ concentrations were inversely correlated with TC, and/or TG, and/or LDL-C after adjusting for confounders.

In contrast, the $25(\mathrm{OH}) \mathrm{D}$ concentrations were found to be positively correlated with apoA-I and/ or HDL-C concentrations in British Bangladeshis [24], patients in the USA [17], and Black American and Caucasian children [25]. Moreover, the $25(\mathrm{OH}) \mathrm{D}$ concentration was also found to be positively correlated with TC, and/or LDL-C levels in China [10], and obese adolescent women [26]. Nevertheless, some studies demonstrated no association between serum 25(OH)D and LDL-C, and HDL-C levels, as well as lipid profiles in postmenopausal women [27] and Iranian children and adults [28].

In this study, BMI, WC, visceral fat rating, percentage fat, and fat mass were significantly higher in hypovitaminosis D compared to vitamin D sufficiency in women. In addition, there was a negative correlation between serum 25(OH)D levels and BMI, WC, visceral fat rating, percentage fat, and fat mass in women. Our findings were consistent with the previous studies in which the inverse correlation between serum 25(OH)D and BMI, and/or adiposity was observed in black and white adolescents in the USA [37], Hispanic and African American adults [38], adults in the Framingham Heart Study [39], and young women in Canada [40]. This is probably due to the decreased bioavailability of vitamin $D$ because vitamin $D$ is fat soluble and can be deposited in adipose tissue [41]. Nevertheless, no association between plasma 25(OH)D and body adiposity was observed in adolescent girls in China [42], nor in children and adolescents in the USA [43]. Altogether, we suggest that such inconsistent results between serum 25(OH)D and lipid levels and body composition may result from several factors, e.g. age, gender, BMI, menopausal status, underlying diseases, ethnicity, environmental factors, and genetic factors.

Although, the mechanism in which vitamin D affects lipid levels is still unclear, several mechanisms have been proposed. First, vitamin D could affect serum lipids by enhancing intestinal calcium absorption and result in increased serum calcium. The increased calcium level may reduce formation and secretion of hepatic TG and intestinal absorption of fatty acid [44]. Second, serum calcium could enhance faecal fat excretion and the secretion of bile acids and then may reduce the cholesterol levels $[45,46]$. Third, low serum $25(\mathrm{OH}) \mathrm{D}$ concentrations were associated with increased parathyroid hormone concentrations. Hyperparathyroidism promoted lipogenesis in adipocytes, decreased lipolysis, decreased lipoprotein lipase activity, decreased peripheral removal of TG, and activated microsomal TG transfer protein, which leads to TG elevation $[44,47]$. Fourth, vitamin $D$ deficiency was found to be associated with impaired $\beta$-cell function and insulin resistance, which leads to an increase in TG level and a decrease in HDL-C level [48]. Finally, vitamin D can regulate the lipid levels through the increased expression of VLDL receptor gene [49].

In the present study, the association between 25(OH)D levels and serum lipids was more pronounced in women than in men. This may be due to the low number of men, which is one of the limitations in this study. In addition, behaviour lifestyles that may influence serum lipids and $25(\mathrm{OH}) \mathrm{D}$ levels may be different among genders. Moreover, the prevalence of hypovitaminosis D in men was also significantly lower than in women $(28.28 \%$ vs. $59.38 \%$, respectively, $p<0.001)$. Another limitation is the study's cross-sectional design; thus, it may not prove the cause and effect of the relationship between serum vitamin D and lipid profiles. However, our study has a clear strength because it recorded several confounders for vitamin D status.

In conclusion, vitamin D sufficiency may reduce the risk for hypertriglyceridaemia and reduced HDL-C, particularly in women, suggesting that vitamin D sufficiency may have beneficial effects on lipid levels and a decreased risk for CVD in Thai women. 


\section{Acknowledgments}

We would like to thank to all participants in this study and the staff of the Centre for Scientific and Technological Equipment, Walailak University, who helped in the specimen collection and laboratory procedures. This work was supported by the Walailak University fund (WU58111, WU59124).

\section{Conflict of interest}

The authors declare no conflict of interest.

\section{References}

1. McLauglin J, Holick MF. Aging decreases the capacity of human skin to produce vitamin $\mathrm{D}_{3}$. J Clin Invest 1995; 76: 1536-8.

2. Salamone LM, Dallal GE, Zantos D, Makrauer F, Dawson-Hughes B. Contributions of vitamin D intake and seasonal sunlight exposure to plasma 25-hydroxyvitamin D concentration in elderly women. Am J Clin Nutr 1994; 59: 80-6.

3. Holick MF. Vitamin D deficiency. N Engl J Med 2007; 357 266-81.

4. Holick MF. Calcium plus vitamin D and the risk of colorectal cancer. N Engl J Med 2006; 354: 2287-8.

5. Stojanovic Ol, Lazovic M, Lazovic M, Vuceljic M. Association between atherosclerosis and osteoporosis, the role of vitamin D. Arch Med Sci 2011; 7, 2: 179-88.

6. Chiu KC, Chu A, Go VL, Saad MF. Hypovitaminosis D is associated with insulin resistance and $\beta$ cell dysfunction. Am J Clin Nutr 2004; 79: 820-5.

7. White JH. Vitamin D signaling, infectious diseases, and regulation of innate immunity. Infect Immun 2008; 76 : 3837-43.

8. Faridi KF, Lupton JR, Martin SS, et al. Vitamin D deficiency and non-lipid biomarkers of cardiovascular risk. Arch Med Sci 2017; 13: 732-7.

9. Wang C. Role of vitamin D in cardiomefigolic diseases. J Diabetes Res 2013; 2013: 243934

10. Wang Y, Si S, Liu J, et al. The associations of serum lipids with vitamin D status. PLoS One 2016; 11: e0165157.

11. Ge H, Sun H, Wang T, et al. The association between serum 25-hydroxyvitamin $D_{3}$ concentration and serum lipids in the rural population of China. Lipids Health Dis 2017; 16: 215

12. Kwon HN, Lim H. Relationship between serum vitamin $D$ status and metabolic risk factors among Korean adults with prediabetes. PLoS One 2016; 11: e0165324.

13. Mansuri S, Badawi A, Kayaniyil S, et al. Associations of circulating 25(OH)D with cardiometabolic disorders underlying type 2 diabetes mellitus in an Aboriginal Canadian community. Diabetes Res Clin Pract 2015; 109: 440-9.

14. Zhang MC, Li HX, Liu HM, et al. Serum vitamin D is low and inversely associated with LDL cholesterol in the Kazak ethnic population: a cross-sectional study. Med Sci Monit 2014; 20: 1274-83.

15. Sun X, Cao ZB, Tanisawa K, et al. Associations between the serum $25(\mathrm{OH}) \mathrm{D}$ concentration and lipid profiles in Japanese men. Atheroscler Thromb 2015; 22: 355-62.

16. Dziedzic EA, Przychodzeń S, Dąbrowski M. The effects of vitamin $\mathrm{D}$ on severity of coronary artery atherosclerosis and lipid profile of cardiac patients. Arch Med Sci 2016; 12: 1199-206.
17. Glueck CJ, Jetty V, Rothschild M, et al. Associations between serum 25-hydroxyvitamin D and lipids, lipoprotein cholesterols, and homocysteine. N Am J Med Sci 2016; 8: 284-90.

18. Lupton JR, Faridi KF, Martin SS, et al. Deficient serum 25-hydroxyvitamin $D$ is associated with an atherogenic lipid profile: the very large database of lipids (VLDL-3) study. J Clin Lipidol 2016; 10: 72-81.

19. Karhapää P, Pihlajamäki J, Pörsti I, et al. Diverse associations of 25-hydroxyvitamin D and 1,25-dihydroxy-vitamin D with dyslipidaemias. J Intern Med 2010; 268: 604-10.

20. Jungert A, Roth HJ, Neuhauser-Berthold M. Associations of serum 25-hydroxycholecalciferol and parathyroid hormone with serum lipids differ by sex and vitamin $D$ status. Public Health Nutr 2015; 18: 1684-91.

21. Botella-Carretero Jl, Alvarez-Blasco F, Villafruela JJ, Balsa JA, VaÂzquez C, Escobar-Morreale HF. Vitamin D deficiency is associated with the metabolic syndrome in morbid obesity. Clin Nutr 2007; 26: 573-80.

22. Kumaratne M, Early G, Cisneros J. Vitamin D deficiency and association with body mass index and lipid levels in Hispanic American adolescents. Glob Pediatr Health 2017; 4: 2333794X17744141.

23. Vogt S, Baumert J, Peters A, Thorand B, Scragg R. Effect of waist circumference on the association between serum 25-hydroxyvitamin $D$ and serum lipids: results from the National Health and Nutrition Examination Survey 2001-2006. Public Health Nutr 2017; 20: 1797-806.

24. John WG, Noonan K, Mannan N, Boucher BJ. Hypovitaminosis $D$ is associated with reductions in serum apolipoprotein A-I but not with fasting lipids in British Bangladeshis. Am J Clin Nutr 2005; 82: 517-22.

25. Rajakumar K, de las Heras J, Chen TC, Lee S, Holick MF, Arslanian SA. Vitamin D status, adiposity, and lipids in black American and Caucasian children. J Clin Endocrinol Metab 2011; 96: 1560-7.

26. Ashraf AP, Alvarez JA, Gower BA, Saenz KH, McCormick KL. Associations of serum 25-hydroxyvitamin $D$ and components of the metabolic syndrome in obese adolescent womens. Obesity 2011; 19: 2214-21.

27. Chacko SA, Song Y, Manson JE, et al. Serum 25-hydroxyvitamin D concentrations in relation to cardiometabolic risk factors and metabolic syndrome in postmenopausal women. Am J Clin Nutr 2011; 94: 209-17.

28. Nouri Saeidlou S, Vahabzadeh D, Babaei F, Vahabzadeh Z. Seasonal variations of vitamin $D$ and its relation to lipid profile in Iranian children and adults. J Health Popul Nutr 2017; 36: 21.

29. Sordyl J, Kopyta I, Sarecka-Hujar B, Francuz T, Matusik P, Matecka-Tendera E. Lipid levels and selected biomarkers of vascular changes in children with idiopathic headaches - a preliminary report. Arch Med Sci 2019; 15: $120-5$.

30. Jäger B, Piackova E, Haller PM, et al. Increased platelet reactivity in dyslipidemic patients with coronary artery disease on dual anti-platelet therapy. Arch Med Sci 2019; 15: 65-71.

31. Jeenduang N, Whanmasae S, Seepawin P, Kullabootr S. The prevalence of dyslipidemia among a rural Thai population in the Nakhon Si Thammarat province. J Med Assoc Thai 2013; 96: 992-1000.

32. Jeenduang N, Sriprachan C, Plyduang T, et al. Vitamin D status and its associated factors in rural subjects in $\mathrm{Na}$ khon Si Thammarat Province, Southern Thailand. J Med Assoc Thai 2018; 101: 397-404. 
33. Chailurkit LO, Aekplakorn W, Ongphiphadhanakul B. Regional variation and determinants of vitamin $D$ status in sunshine-abundant Thailand. BMC Public Health 2011; 11: 853.

34. Expert Panel on Detection, Evaluation, and Treatment of High Blood Cholesterol in Adults. Executive Summary of the Third Report of the National Cholesterol Education Program (NCEP) Expert Panel on Detection, Evaluation, and Treatment of High Blood Cholesterol in Adults (Adult Treatment Panel III). JAMA 2001; 285: 2486-97.

35. Holick MF, Binkley NC, Bischoff-Ferrari HA, et al. Endocrine Society. Evaluation, treatment, and prevention of vitamin D deficiency: an Endocrine Society clinical practice guideline. J Clin Endocrinol Metab 2011; 96: 1911-30.

36. Sangkaew B, Nuinoon M, Jeenduang N. Association of vitamin $D$ receptor gene polymorphisms with serum 25(OH)D levels and metabolic syndrome in Thai population. Gene 2018; 659: 59-66.

37. Dong Y, Pollock N, Stallmann-Jorgensen IS, et al. Low 25-hydroxyvitamin D levels in adolescents: race, season, adiposity, physical activity, and fitness. Pediatrics 2010; 125: 1104-11.

38. Cheng S, Massaro JM, Fox CS, et al. Adiposity, cardiometabolic risk, and vitamin D status: the Framingham Heart Study. Diabetes 2010; 59: 242-8.

39. Young KA, Engelman CD, Langefeld CD, et al. Association of plasma vitamin D levels with adiposity in Hispanic and African Americans. J Clin Endocrinol Metab 2009; 94: 3306-13.

40. Kremer R, Campbell PP, Reinhardt T, Gilsanz V. Vitamin $D$ status and its relationship to body fat, final height, and peak bone mass in young women. J Clin Endocrinol Metab 2009; 94: 67-73.

41. Wortsman J, Matsuoka LY, Chen TC, Lu Z, Holick MF. Decreased bioavailability of vitamin D in obesity. Am J Clin Nutr 2000; 72: 690-3.

42. Foo LH, Zhang Q, Zhu K, et al. Relationship between vitamin D status, body composition and physical exercise of adolescent girls in Beijing. Osteoporos Int 2009; 20: 417-25.

43. Weng FL, Shults J, Leonard MB, Stallings VA, Zemel BS. Risk factors for low serum 25-hydroxyvitamin $D$ concentrations in otherwise healthy children and adolescents. Am J Clin Nutr 2007; 86: 150-8.

44. Cho HJ, Kang HC, Choi SA, Ju YC, Lee HS, Park HJ. The possible role of $\mathrm{ca} 2+$ on the activation of microsomal triglyceride transfer protein in rat hepatocytes. Biol Pharm Bull 2005; 28: 1418-23.

45. Christensen R, Lorenzen JK, Svith CR, et al. Effect of calcium from dairy and dietary supplements on faecal fat excretion: a meta-analysis of randomized controlled trials. Obes Rev 2009; 10: 475-86.

46. Jiang W, Miyamoto T, Kakizawa T, et al. Inhibition of LXRalpha signaling by vitamin $D$ receptor: possible role of VDR in bile acid synthesis. Biochem Biophys Res Commun 2006; 351: 176-84.

47. Querfeld U, Hoffmann MM, Klaus G, et al. Antagonistic effects of vitamin $D$ and parathyroid hormone on lipoprotein lipase in cultured adipocytes. I Am Soc Nephrol 1999; 10: 2158-64.

48. Karnchanasorn R, Ou HY, Chiu KC. Plasma 25-hydroxyvitamin D levels are favorably associated with beta-cell function. Pancreas 2012; 41: 863-8.

49. Kohno M, Takahashi S, Oida K, et al. 1 alpha,25-dihydroxyvitamin $\mathrm{D}_{3}$ induces very low density lipoprotein receptor mRNA expression in $\mathrm{HL}-60$ cells in association with monocytic differentiation. Atherosclerosis 1997; 133: 45-9. 